\title{
De historisering van de moraal. De Groningse universiteit tussen universiteitsgeschiedenis en bezettingsgeschiedenis
}

\author{
P. A. J. Caljé
}

De titel van dit boek - Academische illusies - bevat een fraaie dubbelzinnigheid. Je zou vermoeden dat de illusies waar het om gaat verwijzen naar de illusies die de universiteit koesterde ongestoord voort te kunnen gaan met haar werk en buiten de politiek te kunnen blijven. Deze ondertonen zitten inderdaad wel in het boek, maar zij maken er niet de kern van uit. Het centrale thema van het boek is het streven naar 'academische gemeenschap.' Van Berkel schetst de opkomst van die gedachte in de jaren dertig als reactie op de tijd van crisis en internationale dreiging, vervolgens hoe grote delen van de Groningse universitaire gemeenschap zich aan dit idee vastklampten in de tijd van de bezetting en tenslotte hoe die gedachte als een leidend beginsel functioneerde bij de zuiveringen na de oorlog. En de auteur is in zijn conclusie duidelijk: die gedachte bleek een illusie te zijn. Voor een belangrijk deel moet de geschiedenis van de Groningse universiteit in oorlogstijd als de geschiedenis van die illusie begrepen worden.

Op basis van dit Leitmotiv heeft Van Berkel een belangrijk en origineel boek vol paradoxen geschreven. Ieder die zich met de universiteiten in de Tweede Wereldoorlog bezig houdt moet zich uiteraard verhouden tot de discussie over goed en fout in de Tweede Wereldoorlog en de visie die Blom daarop ontwikkeld heeft. Dat blijkt ook als we overzien wat er de laatste tijd over de universiteiten in de Tweede Wereldoorlog geschreven is. Knegtmans heeft een Blommiaans boek over de Universiteit van Amsterdam geschreven, waarin de oorlogsgeschiedenis ingebed wordt in een ruimere periode van 1935 tot 1950, geheel conform Bloms gedachte dat de Tweede Wereldoorlog niet als een geïsoleerd moment in de Nederlandse geschiedenis begrepen kan worden. Zondergeld daarentegen heeft met elan het aloude goed/foutschema verdedigd in zijn boek over de Vrije Universiteit in de Tweede Wereldoorlog, en Van Deursen is hem daarin bijgevallen in zijn overzichtsgeschiedenis van die universiteit Een hoeksteen in bet verzuild bestel (Amsterdam, 2005). Van Berkel lijkt zich op het eerste gezicht bij de Blommianen aan te sluiten, maar de originaliteit van het boek is dat er meer aan de hand is.

Op het oog lijkt Van Berkel zich als een degelijk en professioneel historicus op te stellen, die elke periode en zo ook de Tweede Wereldoorlog sine ira et studio wil beschouwen. Een dergelijk historicus ziet het niet als zijn taak te oordelen over het verleden en Van Berkel formuleert zijn uitgangspunt in die termen. Hij neemt het zelfbeeld van de actoren in het verleden als uitgangspunt, 
en hij wil uitdrukkelijk geen bezettingsgeschiedenis maar universiteitsgeschiedenis bedrijven. Ook hij neemt zijn periode ruimer dan de Tweede Wereldoorlog sec. $\mathrm{Bij}$ hem loopt het verhaal van 1930 tot 1950 . Hij schetst een universiteit, die in feite een eilandenrijk was vol autonome instituten en die zich er op voorstond de politiek buiten de deur te houden. Onder invloed van de crisis en de dreiging van Duitsland ontstaat een verlangen naar meer gemeenschap op nationaal en academisch vlak dat aanvankelijk als iets a-politieks werd gezien, maar dat Van Berkel terecht als een vorm van politieke betrokkenheid duidt. (99) Hij laat fraai de grote rijkdom aan uitingsvormen van dit verlangen naar gemeenschap zien. Het gaat om de interesse in sociologie maar ook om lichamelijke opvoeding, om de volkshogeschoolbeweging maar ook om volkskunde, om het Barthianisme maar ook om het streven de verdeelde studentenwereld te herenigen. In dat kader past ook de herleving van het ideaal van de academische gemeenschap, waarin de grenzen tussen de disciplines worden overstegen, waarin hoogleraren dicht bij de studenten staan, waarin de universiteit zich de problemen van de samenleving aantrekt en waarin de universiteit niet alleen vakkennis overdraagt maar ook aan persoonlijkheidsvorming doet. Dit verlangen naar gemeenschap noemt Van Berkel 'tendentieel ... antimodern, antiliberaal en in sommige gevallen ook antidemocratisch.' (105) Deze evaluatie lijkt me niet helemaal onproblematisch. $\mathrm{Zij}$ is natuurlijk waar voor zover het om een cultuur van vernieuwing gaat van een samenleving die men best modern, liberaal en democratisch kan noemen. Maar men zou deze beweging onrecht doen als men hem zou begrijpen als een in wezen reactionaire beweging, die verlangend naar het verleden terugkijkt. Een van de paradoxen van modernisering is immers dat vernieuwing en dus modernisering niet zelden geïnspireerd wordt door een teruggrijpen op oudere waarden. Dat dit meer is dan alleen een woordenstrijd zal later blijken.

De aanpak van Van Berkel de geschiedenis van de universiteit in oorlogstijd niet primair als bezettingsgeschiedenis maar als universiteitsgeschiedenis te beschouwen en vooral te waken voor oordelen die vanuit een post-Holocaustbewustzijn zijn ingegeven levert voor de bezettingsperiode een aantal nieuwe oordelen op. De strijd om de Kant-Gesellschaft tussen de latere NSB'er Van der Vaart Smit en Leo Polak wordt in veel genuanceerdere termen beschreven. Polak, die het eerste slachtoffer van de Duitsers onder de hoogleraren zou worden, komt in dit boek als een fel en nogal onverantwoordelijk heethoofd naar voren, die een deel van zijn tragisch lot aan zichzelf te wijten heeft. Kapteyn, de rectormagnificus die voor Polak belastende brieven in de handen van de Duitsers speelde, wordt hiermee gedeeltelijk vrijgepleit, al blijft Kapteyn ook volgens Van Berkel grove nalatigheid en onzorgvuldigheid te verwijten.

Omdat voor de president-curator de universiteit in de oorlogsjaren slecht bereikbaar was, lag de leiding van de universiteit feitelijk in handen van de secretaris van het College van curatoren, de 28 -jarige oud-Corpspraeses J. C. H. Cluysenaer. In zekere zin is hij de hoofdpersoon van het boek. Hij zette de lijnen uit, en meer dan wie ook representeerde hij de universiteit naar buiten toe. Meer dan een groot leider was hij vooral een handig ritselaar die probeerde te redden 
wat er te redden viel door zo min mogelijk aanstoot te geven en zich bij het onvermijdelijke neer te leggen. Het was zeker een man met principes - hoewel hij van oorsprong nogal Duitsgezind was, stelde hij zich in de oorlog principieel Nederlands op - maar een Prinzipienreiter was het allerminst. Hij behoorde tot degenen die de Nederlandse samenleving na de bezetting binnen de gestelde kaders zo veel mogelijk wilden laten doorfunctioneren. Zijn verantwoordelijkheid voor zijn instituut, en wat hij als de eer daarvan beschouwde stond bij hem voorop, niet een principiële stellingname in de nieuwe omstandigheden. Ook probeerde hij zijn verantwoordelijkheid te nemen als het om zijn mensen ging, maar hij lijkt daarin toch minder ver gegaan te zijn dan de leiding van de Vrije Universiteit. Al met al was Cluysenaer een klassiek voorbeeld van accommodatiepolitiek, zoals die door Kossmann is omschreven (De Lage Landen, II, 153159). Hij werkte probleemloos mee aan de Ariërsverklaring. In studentenprotesten zag hij niets. Pas toen de nazificatie van de universiteit op gang kwam begon hij die doelbewust te dwarsbomen voor zover dat binnen de gestelde kaders mogelijk was.

Het boek laat zich ook lezen als een studie naar ethiek in de praktijk. De figuur Cluysenaer representeert dan een overigens hier niet geëxpliciteerde ontwikkeling, die een bepaald soort Verantwortungsethik in de oorlog doormaakte. Hij staat in dit opzicht tegenover mensen als Rutgers en Oranje aan de Vrije Universiteit die niet vanuit de eer van de instelling maar vanuit hun geloof opereerden en veel gemakkelijker als helden beschreven kunnen worden - zoals Zondergeld ook doet.

Maar feitelijk is de hele geschiedenis tot 1943 de opmaat tot waar het in dit boek vooral om gaat: de strijd om de loyaliteitsverklaring en de beslissing van de Raad van Negen - de vertegenwoordigers van de senaten van de traditionele studentenverenigingen - de studenten die deze verklaring tekenden als deserteurs en landverraders te beschouwen. Terecht stelt Van Berkel dat dit het keerpunt in de geschiedenis van de Nederlandse universiteiten tijdens de Tweede Wereldoorlog was. (319) De consequentie was dat het universitaire leven vrijwel geheel stil kwam te liggen en dat de universiteiten feitelijk ophielden te bestaan. Maar dit moment is ook een keerpunt in het boek. Er komt een tweede dimensie bij die door de hele opzet zorgvuldig is voorbereid en nu kan worden uitgewerkt. Vanaf dit moment wordt het boek niet alleen maar een geschiedenis van de universiteit in oorlogstijd, maar ook een geschiedenis van de morele oordelen waarmee die geschiedenis is beoordeeld.

Van Berkel polemiseert uitdrukkelijk tegen het goed recht van de Raad van Negen deze morele beslissing voor alle studenten te nemen. Hij ziet in de Raad vooral de vertegenwoordigers van de traditionele studentenverenigingen die zich 'het recht toe-eigenden weer namens alle studenten te spreken en het conflict in termen te gieten die uit hun wereld afkomstig waren.' De Corpora hadden immers al voor de oorlog getracht het streven naar eenheid onder de studenten te gebruiken om zichzelf weer an het hoofd van de Nederlandse studentenwereld te kunnen stellen. Het ideaal van de academische gemeenschap, waarbij de 
universiteit meer dan alleen vakstudie was en de voorbereiding op een carrière was, maar vooral om persoonlijkheidsvorming in morele zin draaide, speelde daar een grote rol bij. Binnen de traditionele studentenverenigingen werd namelijk een uitgewerkt vormingsprincipe gehanteerd. Om die reden weigerden zij verenigingen die een dergelijk vormingsprincipe naar hun overtuiging niet hadden ontwikkeld en die bovendien tegen de groentijd waren, te erkennen, zoals in het geval van de Groningse vereniging van ongeorganiseerden, De Groene Uil. Moraal komt zo in dienst te staan van een oude machtsstrijd. Het morele oordeel wordt hier gehistoriseerd. Het maakt deel uit van een specifieke ideologie.

Het belang van deze episode bleek ook na de oorlog toen de Groningse universiteit weer snel de draad wilde oppakken. Maar daartoe moest er eerst gezuiverd worden. De uitgangspunten van de Raad van Negen waren ook hier richtinggevend. Het werd studenten zwaar aangerekend als zij de loyaliteitsverklaring hadden getekend en zij werden navenant gestraft. Zij werden voor een forse periode uitgesloten en hadden voor de rest van hun leven een smet op hun blazoen. Men zou hier kunnen tegenwerpen dat men dit nu ook niet weer moet overdrijven. Op het gereformeerde VERA gold het als kleinzielig studenten die na hun schorsing terugkeerden in de studentenwereld hun 'misstap' nog eens in te wrijven. Maar geen van de tekenaars zullen achteraf met trots op deze periode in hun leven terugkijken en het is de vraag of dat terecht is. In Groningen zijn de zuiveringsdossiers vrijwel compleet bewaard gebleven en na zorgvuldige bestudering concludeert Van Berkel dat mensen apert onrecht is aangedaan. Men zou hier kunnen opwerpen dat dit nu eenmaal inherent was aan de snelle, ja overhaaste vorm van rechtspraak en aan de geest van bijltjesdag die zich van degenen die zich moreel sterk voelden had meester gemaakt. Maar Van Berkel laat zien dat ook toen het morele oordeel onderdeel uitmaakte van dezelfde machtsstrijd. Het Groninger Corps en vooral hun vertegenwoordiger in de Raad van Negen, Hans van der Leeuw, zette wederom hard in tegen De Groene Uil, die op een gegeven moment zelfs geweerd werd uit de kolommen van het universiteitsblad. Van Berkel plaatst deze machtsstrijd in het kader van het transformatieproces van de universiteit van een elitaire, standsgebonden universiteit naar een functiegeoriënteerde universiteit dat zoals hij stelt tussen 1890 en 1960 zijn beslag kreeg. De conservatieve Raad van Negen representeerde met zijn moralisme de traditionele universiteit. Veel van de tekenaars voelden zich niet met deze traditie verwant en moesten bovendien om sociale en financiële redenen zo snel mogelijk afstuderen. Voor hen had de universitaire graad dus vooral een functionele betekenis.

De centrale these van het boek vond ik overtuigend, vernieuwend en belangwekkend. In feite wordt hier een nieuw paradigma gecreëerd waarmee de geschiedenis van de universiteit in de Tweede Wereldoorlog geduid kan worden. En dat nieuwe paradigma is de vrucht van de twee pijlers waarop de aanpak van Van Berkel rust: de episode niet vanuit het perspectief van de bezettingsgeschiedenis maar van de universiteitsgeschiedenis te beschouwen en vervolgens het 
zelfbeeld van de actoren als uitgangspunt van de analyse te nemen, die dan vervolgens uitmondt in een kritische beschouwing van dit zelfbeeld.

Deze opzet leidt echter ook tot een aantal paradoxen. Dat blijkt bijvoorbeeld in het eerste deel van het boek. Van Berkel wil uitdrukkelijk universiteitsgeschiedenis bedrijven, en geen bezettingsgeschiedenis. Maar juist het vooroorlogse gedeelte heeft toch een beetje het karakter van De Jongs Voorspel. De dynamiek van dit gedeelte is immers gebaseerd op de gedachte hoe een zich als a-politiek beschouwend universitaire gemeenschap onder druk van crisis en internationale dreiging langzaam in de ban komt van gemeenschapsdenken, dat Nederland moest vernieuwen en dat zich na 1940 uitte in aan de oorspronkelijke ideeën van de Nederlandse Unie verwante standpunten. Als men dit gedeelte werkelijk vanuit het standpunt van universiteitsgeschiedenis zou beschrijven dan zou men verwachten dat juist het transformatieproces van een relatief kleine, elitaire, standsgeoriënteerde universiteit naar een massa-universiteit meer aandacht zou krijgen. Maar in het zelfbeeld van de acteurs speelde het besef onderdeel van een dergelijk transformatieproces te zijn kennelijk geen grote rol.

Het gebrek aan aandacht voor de verwevenheid tussen universiteit en samenleving blijkt ook in de analyse waarom de universiteiten in de bezettingstijd zo weinig succesvol wisten te opereren. In het voetspoor van Huizinga wijst hij dan op de duplex ordo in het bestuur van de universiteit - Senaat en Curatoren. Speciaal het College van curatoren, dat als een verlengstuk van de departementale politiek worden beschouwd, acht hij een weeffout in het universitaire bestel. Wederzijds wantrouwen zou dan een krachtige universitaire politiek onmogelijk maken. Sterk academisch leiderschap was zijns inziens eerder van een autonome universiteit te verwachten. Van deze gedachte ben ik niet overtuigd. De universiteit is daarvoor te zeer een eilandenrijk met sterk individualistische hoogleraren die nimmer op één lijn te krijgen zijn. Op geen enkel moment in deze geschiedenis heb je het idee dat er uit het hoogleraarscorps als geheel krachtig moreel leiderschap tegen de Duitse politiek te verwachten viel. Hier blijft Van Berkels analyse te zeer binnen de kaders van de universiteit. Het probleem was namelijk algemener. De universiteiten handelden niet veel anders dan andere grote maatschappelijke instellingen of bedrijven in hun accommodatiepolitiek. Kossmann wijst er op dat België in de Eerste Wereldoorlog nog tot een politiek van onthouding en weigering overging - de universiteiten sloten er bijvoorbeeld hun poorten. Noch in Nederland, noch in België werd daar in 1940 serieus over gedacht - integendeel, het gold juist als een verdienste de maatschappij voort te laten functioneren. Volgens Kossmann toont dit aan dat het economische - hier dan breed genomen - zozeer het primaat over het politieke had gekregen dat zelfs problemen, voortvloeiend uit een bezetting door een immorele overheid, niet effectief in politieke termen werden vertaald.

In het verlengde hiervan geloof ik ook niet zo in het beeld van een a-politieke universiteit in het Interbellum die als gevolg van crisis en internationale dreiging meer politiseerde. Het idee van een principieel a-politieke universiteit behoorde tot het liberale zelfbeeld maar was nooit werkelijkheid. Van Berkel stelt terecht 
dat de nieuwe gemeenschapspolitiek wel degelijk tot stellingname op politiek en maatschappelijk terrein leidde. Maar zo heel veel verschil met de vooroorlogse Groot-Nederlandse beweging was er in dit opzicht niet, en van de studentenafdelingen van het ANV was in 1910 één op de zeven studenten lid (Van den Broeke, Van Hees, Studenten en nationaal gevoel in Nederland, 45). Feitelijk valt het nationalisme buiten de definitie van politiek, die aan de universiteit werd gehanteerd, en dat lijkt me niet verhelderend. Ook wat wij nu - in navolging van De Rooij - metapolitiek zouden noemen past niet in deze definitie. Feitelijk is het hele idee van een a-politieke universiteit een fictie, die ook voor de negentiende eeuw nimmer realiteit is geweest. En dat heeft te maken met twee aspecten van de relatie tussen universiteit en samenleving. Allereerst was en is de universiteit veel nauwer met de samenleving verbonden dan de aanhangers van het idee van de autonome universiteit wilden geloven. De universiteit was en is altijd instrument geweest in de vormgeving van de samenleving en vervulde daardoor altijd een uitgesproken politieke functie. Zo zijn de universiteiten heden ten dage verwikkeld in een veranderingsproces als gevolg van een bewuste politiek van globalisering. En, ten tweede, juist daardoor doen zeker in de geesteswetenschappen politiek geladen thema's telkens weer hun intrede in de collegezalen. Een hoogleraar als Lulofs werd in 1815 benoemd vanuit de gedachte dat hij zijn leerstoel zou gebruiken voor de versterking van de nationale cultuur en de nationale eenwording. Het was op de colleges van Cort van der Linden dat Troelstra de inspiratie kreeg voor zijn wending tot de sociaaldemocratie. De gedachte dat de universiteit een a-politieke instelling was, kan men alleen volhouden als men vasthoudt aan een zeer smalle definitie van politiek die eigen was aan het burgerlijk-liberale zelfbeeld van de hoogleraren.

Ik zou ook minder geneigd zijn dan Van Berkel het verzet uit de kringen van het Corps tegen de nieuwe functionele universiteit maatschappelijk te duiden als een reflex vooral het oude vast te willen houden en het nieuwe tegen te houden. Zo gesteld doemt er een beeld op van domme corpsstudenten die niet inzagen dat zij feitelijk thuishoorden op de schroothoop der geschiedenis (en dat feitelijk nog steeds niet hebben gedaan). De schitterende analyse die Van Berkel heeft gegeven van de wijze waarop hoge morele principes en bevlogen gedachten over de academische gemeenschap en de vormende waarde van de universiteit instrumenteel waren in een machtsstrijd om de universiteit zou ik eerder als een vorm van conservatieve modernisering willen zien, waar conservatieve studenten in een veranderende samenleving naar nieuwe kansen en nieuwe instrumenten zochten om hun visie op de samenleving en de cultuur die daarop voorbereidde te laten prevaleren.

Dit alles levert dan wederom een fraaie paradox op. Van Berkel heeft universiteitsgeschiedenis en geen bezettingsgeschiedenis willen schrijven. Het boek is als universiteitsgeschiedenis goed, maar niet speciaal vernieuwend. Als bezettingsgeschiedenis is het dat wel, juist door de historisering van de moraal die pas mogelijk was door het boek als universiteitsgeschiedenis op te zetten. 
Men kan nog meer paradoxen aanwijzen. Van Berkel wil niet in het traditionele goed/foutschema vervallen. Maar uiteindelijk ontpopt hij zich - het Blommianisme voorbij - als een moralist die met scherpe pen neerzet waar en door wie mensen uit misplaatste morele hoogmoed onrecht is aangedaan, zoals in het geval van de tekenaars. De historisering van de moraal impliceert tegelijk een nieuw moralisme. Moralist is Van Berkel ook in de absurde Plessner-affaire waarin hoogleraren die de hele oorlog vooral slapheid uitstraalden toen de kust veilig was opeens principieel en anti-Duits gingen doen toen de half-jood Plessner, die de oorlog met moeite was doorgekomen, in hun faculteit benoemd moest worden. Van Berkel spreekt er terecht schande van.

Soms gaat zijn moralisme me echter net iets te ver. Historici die in het goed/ foutschema blijven denken en bijvoorbeeld het oordeel van de Raad van Negen over de tekenaars overnemen noemt hij 'slechte historici.' Dat is wel erg gemakkelijk gezegd. Van Berkel creëert een nieuw paradigma en beschouwt nu opeens iedereen die niet van zijn denkbeelden heeft kunnen profiteren als een slecht historicus. Dat is onredelijk. Zijn visie heeft mij overtuigd, maar ik kan me ook voorstellen dat de discussie nog allerminst gesloten is. De historisering van de moraal stelt de moraal ter discussie, maar die moet nog wel gevoerd worden. En dan kan men zich afvragen of er niet toch meer in het goed/foutschema zit dan wij nu misschien denken. Wie het boek van Zondergeld over de Vrije Universiteit heeft gelezen, wordt ondergedompeld in een wereld die in alles afwijkt van de gewone wereld, en waarin andere eisen aan mensen worden gesteld en waarin andere normen en waarden gelden. In deze wereld is men held of schurk. Zonder nu deze kwalificaties over te willen nemen, heeft Zondergeld in diepere zin misschien gewoon gelijk. De Tweede Wereldoorlog was voor Nederland een uitzonderlijke periode zonder effectief legitiem gezag en waarin onzekerheid heerste over de duur van deze uitzonderingstoestand. In die wereld is een verstandige Gesinnungsethik misschien effectiever dan een Verantwortungsethik. Als het boek van Van Berkel iets laat zien, dan is het dat de redelijke en voorzichtige hoogleraren uiteindelijk niet heel veel bereikten met hun beleid van geen aanstoot geven. De eer van de universiteit werd uiteindelijk ook niet gered. Juist de min of meer 'totale instituties' in de richting van Goffmann - de kleine, gesloten, strak georganiseerde gemeenschappen rond een sterke religie of wereldbeschouwing zoals de gereformeerde gemeenschap, de communistische partij of het studentencorps - waren wellicht beter voorbereid op de uitzonderlijke wereld van de Tweede Wereldoorlog dan de redelijke, open en op verantwoordelijkheid voor het maatschappelijke raderwerk gerichte Nederlandse elites. Dit maakt de Tweede Wereldoorlog overigens ongeschikt als exemplarisch voorbeeld voor gedrag voor tijden waarin er wèl stabiel, effectief legitiem gezag heerst.

Maar de mooiste paradox vinden we aan het einde. Het boek is op het oog een poging tot deconstructie van het bevlogen denken van de jaren dertig en veertig in termen van een academische gemeenschap. Maar tegelijk schemert er op sommige momenten tussen de koele analytische regels ook een verlangen naar 
gemeenschap door. Zo lezen wij dat het gezamenlijk voluit zingen van bekende liederen kenmerkend is voor sterke gemeenschappen. (174) Op de allerlaatste bladzijde van het boek vraagt de auteur zich af of de universiteit om niet in zielloos functionalisme te vervallen wel zonder het idee van een academische gemeenschap kan - ook al weten wij dat die niet meer dan een illusie is. 'Is het niet een van de mooiste eigenschappen van de westerse cultuur dat wij kunnen geloven in iets waarvan we weten dat het niet bestaat?' Zo eindigt het boek in wijsheid. 
gemeenschap door. Zo lezen wij dat het gezamenlijk voluit zingen van bekende liederen kenmerkend is voor sterke gemeenschappen. (174) Op de allerlaatste bladzijde van het boek vraagt de auteur zich af of de universiteit om niet in zielloos functionalisme te vervallen wel zonder het idee van een academische gemeenschap kan - ook al weten wij dat die niet meer dan een illusie is. 'Is het niet een van de mooiste eigenschappen van de westerse cultuur dat wij kunnen geloven in iets waarvan we weten dat het niet bestaat?' Zo eindigt het boek in wijsheid. 


\title{
Dubbelzinnigheid als historische deugd. Een antwoord aan Knegtmans, Zondergeld en Caljé
}

\author{
KLAAS VAN BERKEL
}

Het is waar: de titel van mijn boek over de Groningse universiteit in oorlogstijd -Academische illusies - is dubbelzinnig. En dat was ook precies de bedoeling. Opzet van het boek was niet om definitieve antwoorden te geven op exact en ondubbelzinnig geformuleerde vragen, maar om te stimuleren tot het nadenken over kwesties die omstreden zijn en ook wel zullen blijven. Het was eerder zo dat ik de zekerheden die in het verleden over de morele en politieke dilemma's in de geschiedenis van universiteiten in oorlogstijd zijn gedebiteerd ter discussie wilde stellen dan dat ik deze wilde vervangen door nieuwe zekerheden. Het boek is daarom in wezen ook niet een historische exercitie: het gaat om vragen die zich aan historische plaatsbepaaldheid lijken te onttrekken ('wat is dat eigenlijk, een universiteit?') en om morele vraagstukken die wel nadrukkelijk door de Duitse bezetting werden opgeroepen, maar eigenlijk van alle tijden zijn - zoals de vraag hoe moraal en macht zich tot elkaar verhouden. Dubbelzinnig, dat wil zeggen op meer dan één manier uit te leggen taalgebruik hoort daarbij en dat althans één recensent begrepen heeft dat dit al in de titel tot uitdrukking komt, stemt mij tot tevredenheid. Een goede titel is het halve werk.

Dat dubbelzinnigheid een historische deugd kan zijn, betekent niet dat er niet correct geciteerd hoeft te worden. Standpunten moeten juist worden weergegeven alvorens ze bekritiseerd of gedeconstrueerd kunnen worden. In dit opzicht had ik van P. J. Knegtmans - hoezeer ik zijn uiteenzetting ook waardeer - iets meer precisie verwacht. Zijn uitgangspunt is mijn claim dat de oorlogsgeschiedenis van de Groningse universiteit meer is dan de geschiedenis van die ene universiteit. In zijn woorden: 'Van Berkel noemt de Rijksuniversiteit Groningen in het midden van de twintigste eeuw een goede representant van de Nederlandse universiteiten in het algemeen', daarbij verwijzend naar pagina 9 van het boek. Wie die bewuste pagina opslaat, zal constateren dat deze samenvatting in meer dan een opzicht onvolledig is en daarom geen recht doet aan wat ik beweerde. Om te beginnen nam ik - voordat ik over representativiteit begon - een disclaimer op: wat ik over het representatieve van de Groningse universiteit opmerkte, gebeurde 'half in ernst, half in scherts.' Bovendien had ik het niet over het midden van de twintigste eeuw, maar over de twintigste eeuw in het algemeen. Ten slotte gaf ik een argument voor mijn stelling dat in de samenvatting geheel verdwenen is: 'Groningen was het meest universiteit', waarmee ik bedoelde dat de idee van de universiteit als academische gemeenschap, in functionele afzondering verbonden met de samenleving als geheel, in de Groningse universiteitsgeschiedenis wel heel pregnant naar voren kwam. Dit 


\title{
Dubbelzinnigheid als historische deugd. Een antwoord aan Knegtmans, Zondergeld en Caljé
}

\author{
KLAAS VAN BERKEL
}

Het is waar: de titel van mijn boek over de Groningse universiteit in oorlogstijd -Academische illusies - is dubbelzinnig. En dat was ook precies de bedoeling. Opzet van het boek was niet om definitieve antwoorden te geven op exact en ondubbelzinnig geformuleerde vragen, maar om te stimuleren tot het nadenken over kwesties die omstreden zijn en ook wel zullen blijven. Het was eerder zo dat ik de zekerheden die in het verleden over de morele en politieke dilemma's in de geschiedenis van universiteiten in oorlogstijd zijn gedebiteerd ter discussie wilde stellen dan dat ik deze wilde vervangen door nieuwe zekerheden. Het boek is daarom in wezen ook niet een historische exercitie: het gaat om vragen die zich aan historische plaatsbepaaldheid lijken te onttrekken ('wat is dat eigenlijk, een universiteit?') en om morele vraagstukken die wel nadrukkelijk door de Duitse bezetting werden opgeroepen, maar eigenlijk van alle tijden zijn - zoals de vraag hoe moraal en macht zich tot elkaar verhouden. Dubbelzinnig, dat wil zeggen op meer dan één manier uit te leggen taalgebruik hoort daarbij en dat althans één recensent begrepen heeft dat dit al in de titel tot uitdrukking komt, stemt mij tot tevredenheid. Een goede titel is het halve werk.

Dat dubbelzinnigheid een historische deugd kan zijn, betekent niet dat er niet correct geciteerd hoeft te worden. Standpunten moeten juist worden weergegeven alvorens ze bekritiseerd of gedeconstrueerd kunnen worden. In dit opzicht had ik van P. J. Knegtmans - hoezeer ik zijn uiteenzetting ook waardeer - iets meer precisie verwacht. Zijn uitgangspunt is mijn claim dat de oorlogsgeschiedenis van de Groningse universiteit meer is dan de geschiedenis van die ene universiteit. In zijn woorden: 'Van Berkel noemt de Rijksuniversiteit Groningen in het midden van de twintigste eeuw een goede representant van de Nederlandse universiteiten in het algemeen', daarbij verwijzend naar pagina 9 van het boek. Wie die bewuste pagina opslaat, zal constateren dat deze samenvatting in meer dan een opzicht onvolledig is en daarom geen recht doet aan wat ik beweerde. Om te beginnen nam ik - voordat ik over representativiteit begon - een disclaimer op: wat ik over het representatieve van de Groningse universiteit opmerkte, gebeurde 'half in ernst, half in scherts.' Bovendien had ik het niet over het midden van de twintigste eeuw, maar over de twintigste eeuw in het algemeen. Ten slotte gaf ik een argument voor mijn stelling dat in de samenvatting geheel verdwenen is: 'Groningen was het meest universiteit', waarmee ik bedoelde dat de idee van de universiteit als academische gemeenschap, in functionele afzondering verbonden met de samenleving als geheel, in de Groningse universiteitsgeschiedenis wel heel pregnant naar voren kwam. Dit 